\title{
A current affair: electrotherapy in wound healing
}

Jerome Hunckler

Achala de Mel

UCL Division of Surgery and Interventional Sciences, Faculty of Medical Sciences, University College London, London, UK
Correspondence: Achala de Mel UCL Division of Surgery and Interventional Sciences, Faculty of Medical Sciences, University College London, Pond Street, London, NW3 2QG, UK Tel +442074354608

Email demelach@gmail.com
This article was published in the following Dove Press journal: Journal of Multidisciplinary Healthcare

20 April 2017

Number of times this article has been viewed
Abstract: New developments in accelerating wound healing can have immense beneficial socioeconomic impact. The wound healing process is a highly orchestrated series of mechanisms where a multitude of cells and biological cascades are involved. The skin battery and current of injury mechanisms have become topics of interest for their influence in chronic wounds. Electrostimulation therapy of wounds has shown to be a promising treatment option with nodevice-related adverse effects. This review presents an overview of the understanding and use of applied electrical current in various aspects of wound healing. Rapid clinical translation of the evolving understanding of biomolecular mechanisms underlying the effects of electrical simulation on wound healing would positively impact upon enhancing patient's quality of life. Keywords: electrotherapy, wound healing, infection, bioelectric current, exogenous current, bioelectric medicine, electrical stimulation, chronic wound, acute wound

\section{Introduction}

Efficacious wound healing is still a clinical challenge and the complications associated with impairment in wound healing carry a great financial burden as well as a negative impact on patient lifestyle. Among chronic wounds, the highest prevalence lays in the venous leg ulcer, diabetic foot/leg wound (DFU), and pressure ulcer categories. Complex chronic wounds, such as diabetic ulcers, have a major long-term impact on the morbidity, mortality, and quality of patient's life. In 2010, the NHS in England has spent around $£ 650$ million on foot ulcer management and amputation, which represent $\sim 0.5 \%$ of its budget. ${ }^{1}$ In the USA, $33 \%$ of the $\$ 116$ billion total health care spend on diabetes is on the management of foot ulceration. ${ }^{2}$ In Europe, cost of wound management accounts for $2 \%-4 \%$ of the health care budgets. ${ }^{3}$ Furthermore, Diabetes UK estimates that by 2030 , nearly 552 million people worldwide will develop diabetes. ${ }^{4}$ Estimates indicate that $15 \%$ of all diabetes patients will develop DFUs and of that $84 \%$ leading to lower leg amputations.

The wound healing process is influenced by several local and systemic factors ${ }^{5,6}$ (Figure 1), and is complex with a multitude of biomolecular pathways, but comprises four distinct yet interrelated phases: hemostasis, inflammation, proliferation, and remodeling (Figures 2 and 3). The human epidermis exhibits a natural endogenous "battery" that generates a small electric current when wounded. ${ }^{7,8}$ Healing is arrested when the flow of current is disturbed or when the current flow is stopped during prolonged opening. Different treatment strategies exist for the management of chronic wounds; some are invasive, such as wound debridement and skin substitute therapy, while others are noninvasive, such as compression bandaging, wound dressing, 


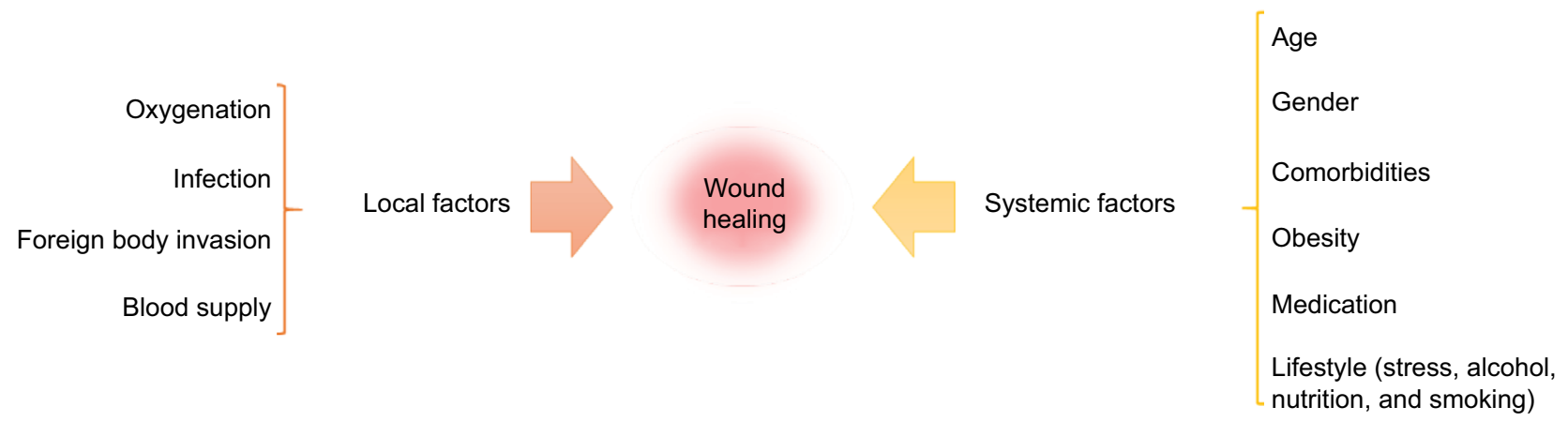

Figure I Local and systemic factors that influence wound healing.

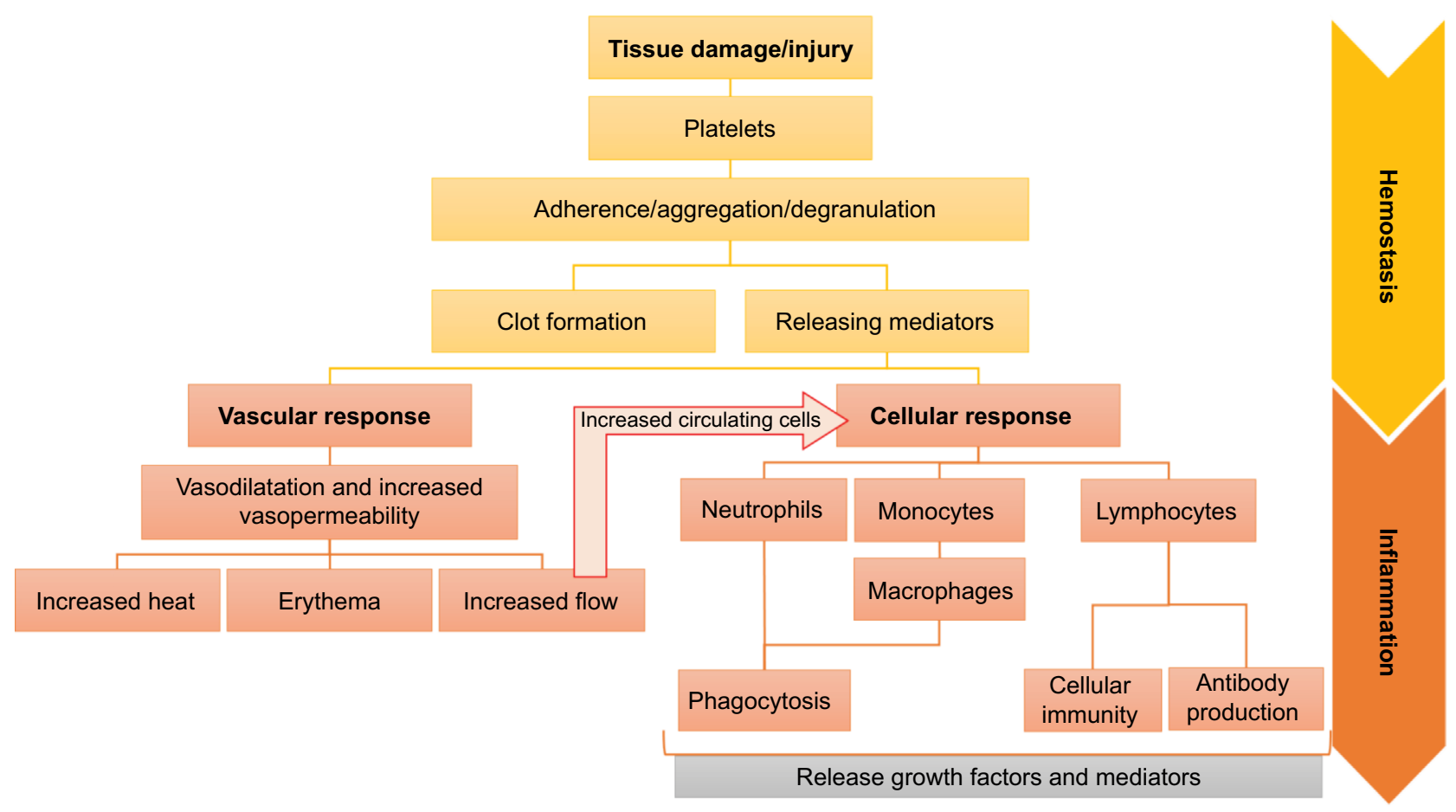

Figure 2 Hemostasis and inflammation phases of wound healing.

Notes: After an injury, the hemostasis (yellow) leads to cessation of bleeding. The platelets adhere to form a clot and release mediators to induce additional platelet aggregation and mediate the phases of the healing process. The released mediators trigger the inflammatory phase (orange), divided into a vascular and a cellular response. Neutrophils, macrophages, and lymphocytes are cleaning the wound while the surrounding vascular system dilates, allowing more blood volume and circulating cells to be recruited. Neutrophils and macrophages migrate toward the wound in order to clear the area of debris, bacteria, and dead tissues, also known as phagocytosis. In addition to providing cellular immunity and antibody production, lymphocytes act as mediators within the wound environment through the secretion of cytokines and direct cell-tocell contact.

hyperbaric oxygen therapy, negative pressure therapy, ultrasound, and electrostimulation therapy (EST). EST is relatively cost-effective, safe, painless, and easy to use. EST mimics the natural current of injury and jump starts or accelerate the healing process.

The effect of electrical stimulation (ES) has been tested in vitro on different types of cells involved in wound healing, such as macrophages, ${ }^{9}$ fibroblasts, ${ }^{10-14}$ epidermal cells, ${ }^{15-20}$ bacteria, ${ }^{21-23}$ and endothelial cells ${ }^{24-26}$ that have demonstrated changes in cell migration, proliferation, and orientation, increase in proteins and DNA synthesis, and antibacterial effects. When applied on in vivo models ${ }^{27-40}$ and clinical stud- ies, ${ }^{41-61}$ EST has shown positive effects on wound closure and healing rate. Other outcomes, such as increased angiogenic response, wound contraction, and antibacterial effects have also been reported. However, there is a considerable variation in study design, outcome measures, ES parameters, type of current, type of wound, and treatment duration, and dose, thus presenting further questions on the most optimal approach for the treatment of cutaneous wound healing is crucial. This review presents an overview of the state-of-the-art medical technology applications and technologies associated with "smart" materials that can be potentially exploited to mimic the current of injury for wound healing and skin regeneration, 


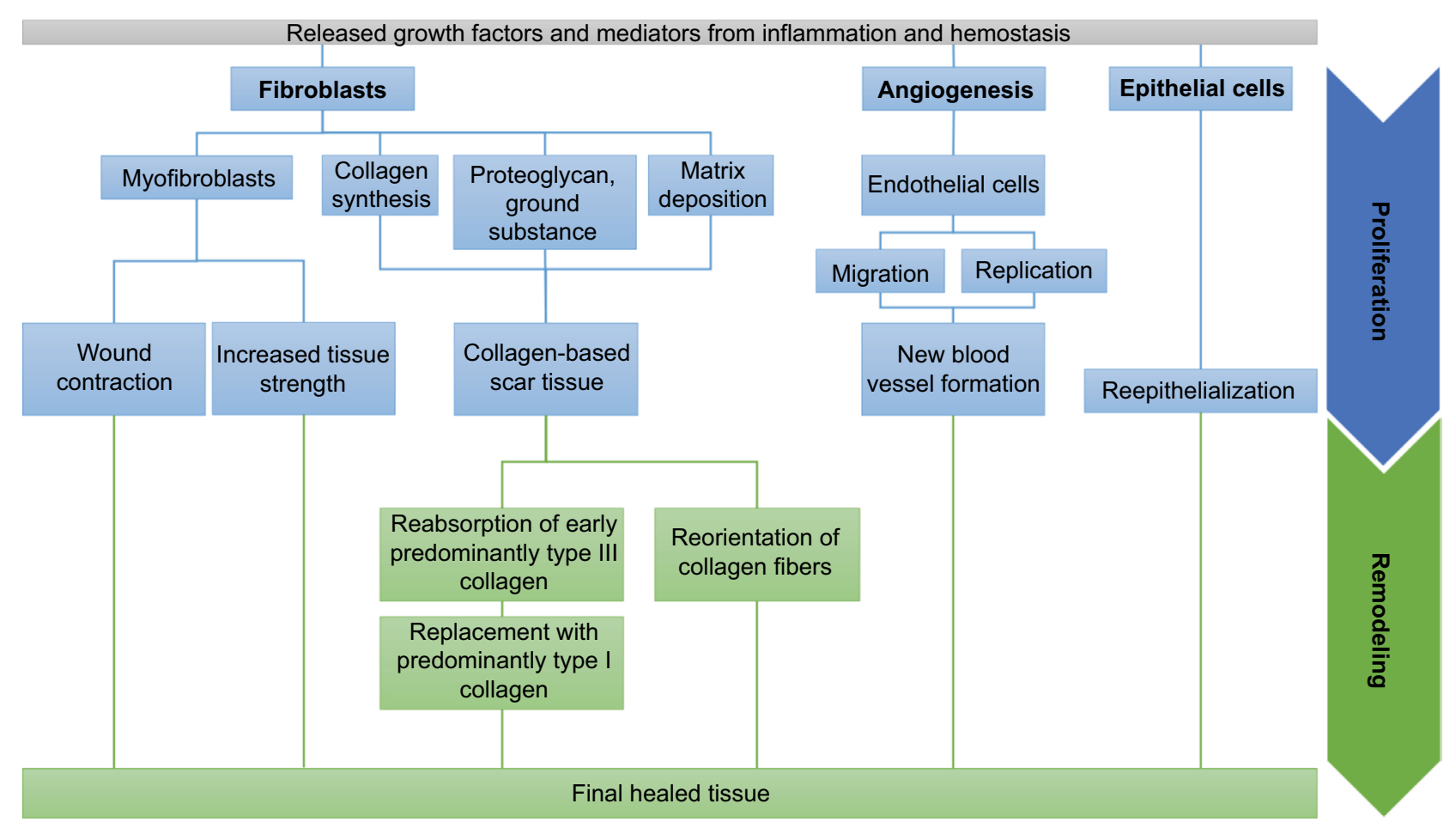

Figure 3 Proliferation and remodeling phases of wound healing.

Notes: The proliferation phase (blue) is a reconstruction step, where cells are working to form granulation tissues and restore a functional skin. Several events are conducted simultaneously: angiogenesis, granulation tissue formation, wound contraction, collagen deposition, and reepithelialization. Activated endothelial cells create new blood vessels by proliferating and migrating toward the source of the angiogenesis stimulus. The epidermal cells proliferate and migrate at the wound edge to initiate wound recovery. Stimulated fibroblasts synthesize collagen, ground substance, and provisional matrix to create a collagen-based scar tissue. Some of them also differentiate into myofibroblast that contracts and induces mechanical stress inside the wound. During the remodeling phase (green), the matrix is turned over and the wound undergoes more contraction by the myofibroblasts. Collagen is also reorganized and reoriented.

with reports on the therapeutic evidences of their present use in clinical practice.

\section{Endogenous bioelectric current}

It is known that the human body possesses an endogenous bioelectric system that produces natural electrochemical signals in different areas, such as the brain, skin, muscles, heart, and bones. In physiological solution, there are no free electrons to carry the current. Thus, it is carried by charged ions. Across the tissues, asymmetric ionic flows generate electrical potentials (Figure 4A). A transepithelial electric potential, named skin battery, is generated by the movement of ions through $\mathrm{Na}^{+} / \mathrm{K}^{+}$ATPase pumps of the epidermis. ${ }^{20}$

Current of injury, which is essential for normal wound healing (Figure 4B and Video S1), is generated during skin injury. This electrical leak, which is a long-lasting lateral electrical potential, short-circuits the skin battery. $\mathrm{Ca}^{2+}, \mathrm{Na}^{+}$, $\mathrm{K}^{+}$, and $\mathrm{Cl}^{-}$ions are the main components of this electrical current. ${ }^{62}$ The current of injury, measurable $2-3 \mathrm{~mm}$ around the wound and from around 10 to $60 \mathrm{mV},{ }^{8}$ creates an electrical potential directed toward the wound with the negative pole at the wound center and the positive at the edge $e^{20,63}$ and attracts cells toward the injury. The current is sustained in a moist environment and shuts off when a wound dries out. ${ }^{64}$ The link between ionic flux, current of injury, and healing rate has been made in 1983 . Increase in $\mathrm{Cl}^{-}$and $\mathrm{Na}^{+}$influx with $\mathrm{AgNO}_{3}$ in wounded corneal epithelium of rats induced a significant augmentation of the current of injury, resulting in enhanced wound healing. However, rat corneal wounds with furosemide (a component that inhibits $\mathrm{Cl}^{-}$efflux) exhibited a significant diminution of the current of injury, resulting in impaired corneal wounds.

\section{Effects of exogenous electric current on wound healing}

ES is used in several disciplines, such as electroanalgesia for chronic pain control, pacemakers to regulate heartbeat, cochlear stimulation to aid hearing, functional ES to restore mobility in people with paralyzed $\operatorname{limb}(\mathrm{s})$, in addition to enhance wound healing. ${ }^{65}$ In wound healing, four main therapeutic approaches have been identified: direct current (DC), alternative current (AC), pulsed current (PC), and transcutaneous electrical nerve stimulation (TENS; Figure 5A). In each therapeutic approach, different parameters, such as the voltage, 
A

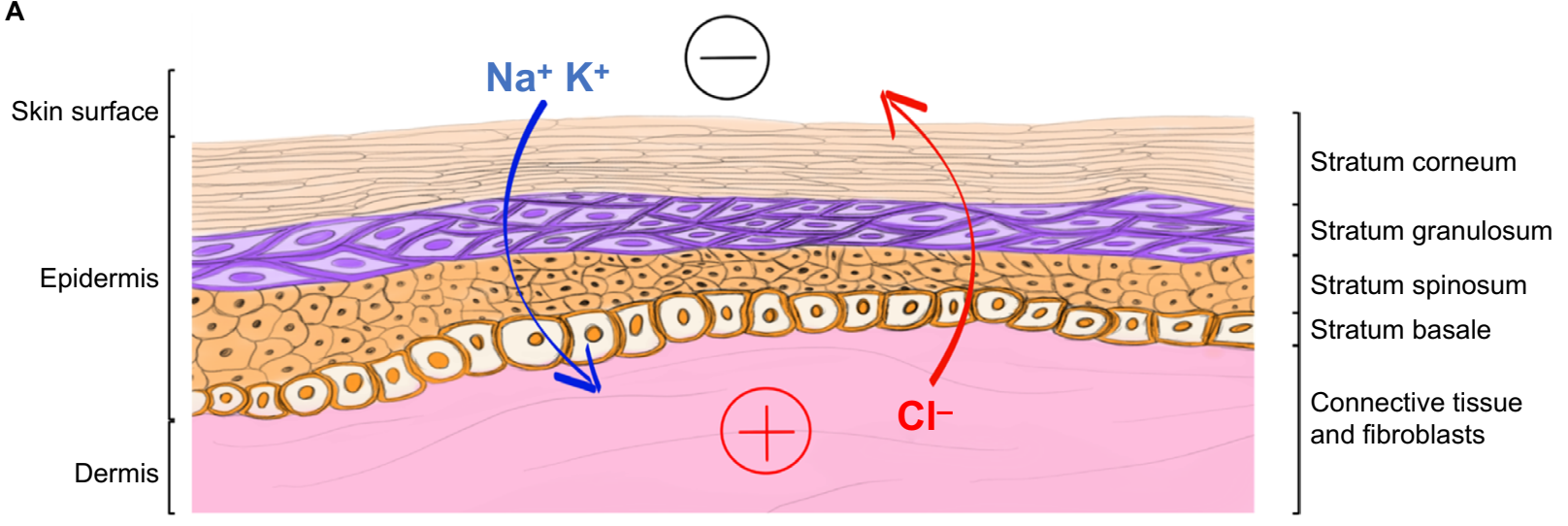

B

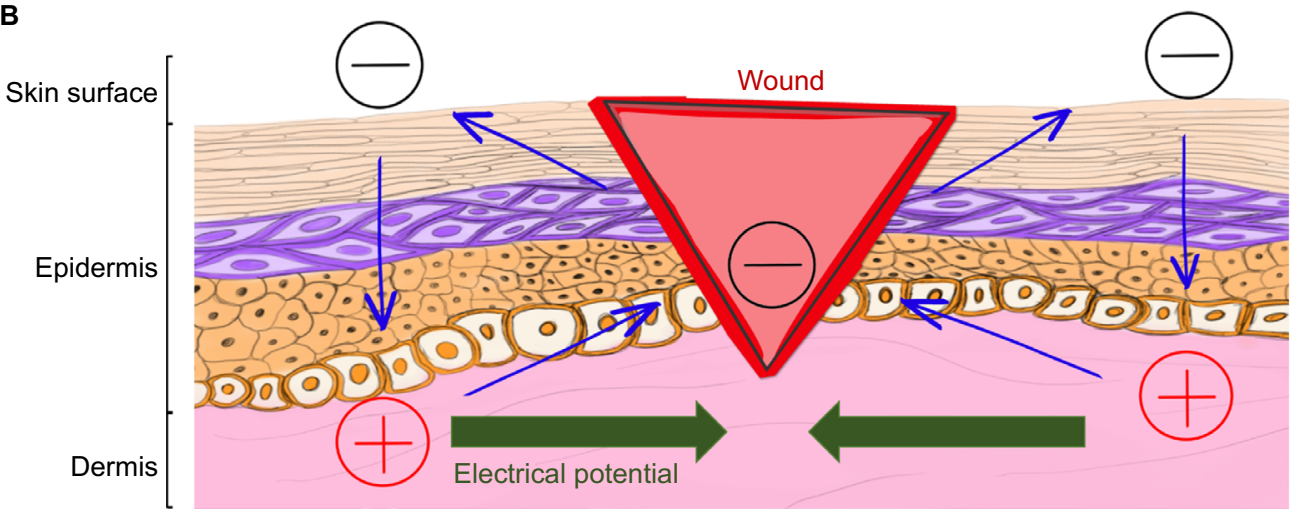

Figure 4 Cutaneous endogenous bioelectric current before and after injury.

Notes: Unbroken skin layers of the epidermis and dermis (A) maintain the skin battery across the body through ionic movement of $\mathrm{Na}^{+}, \mathrm{K}^{+}$, and $\mathrm{Cl}^{-}$, generating a polarity with positive (+) and negative (-) poles. When wounded (B), the current flows out of the wound (blue), generating an endogenous electrical potential (green) with the negative pole $(-)$ in the wound center and the positive pole away from the wound (+). These changes can be viewed in Video SI. Data from Zhao et al.. ${ }^{20}$

duration, frequency, phase, mode, and type of pulse, can be controlled. Depending on the protocol, the impulse amplitude is either preset by the operator at the maximum value according to the patient's sensitivity threshold of the stimulated tissue or can be changed by the patient during the treatment according to personal sensitivity. DC is continuous and simple. If DC is applied for a too long duration and amplitude, DC can cause tissue irritation and damage. On a porcine wound, AC and DC both reduced healing time. ${ }^{37}$ However, DC seemed to be more efficient than $\mathrm{AC}$ to reduce the wound area, and $\mathrm{AC}$ seemed to be more efficient than DC to reduce the wound volume.

$\mathrm{PC}$ is one of the most documented EST. In clinical trials, low voltage, high voltage, degenerative waveform, and short voltage PC (SVPC) have shown positive effects when used on diabetic and chronic ulcers. ${ }^{43-51,55,61}$ One randomly controlled clinical trial (RCT) has tested different durations of stimulation on ulcer patients and showed that 60 and 120 min of stimulation significantly reduced the wound surface area compared to 45 min. ${ }^{42}$ SVPC devices, such as Aptiva Ballet (Lorenz Therapy system) or Naturepulse (Globe Microsystems), generate short voltage impulse patterns. Each impulse is characterized by a specific sharp spike. During the stimulation, frequency, pulse amplitude, and pulse width vary automatically. SVPC increases the circulating vascular endothelial growth factor (VEGF) in the blood during the stimulation and induces nitric oxide formation the day after treatment. ${ }^{66}$ Moreover, SVPC has shown enhanced wound area reduction in the treatment of chronic, venous, and diabetic ulcers, in four RCTs, ${ }^{50,53,54,56}$ but the short period of the studies has not allowed to evaluate the wound healing rate. One $\mathrm{RCT}^{53}$ has used SVPC on chronic leg ulcers with an "until-healed" treatment duration. This duration of treatment allowed to evaluate the wound closure and reported that SVPC enhanced wound closure. TENS is a low- or highfrequency pulsed electrical current that stimulates the peripheral nerves. This stimulation is used in clinical practice for the relief of chronic and acute pain. It is believed that stimulation of the peripheral nerves increases blood flow and could help healing. TENS locally increases the blood flow and VEGF level in healthy and diabetic patients. ${ }^{67-70}$ However, no study has tested the effect of TENS on wound healing.

Figure 5B shows the summary of different methods of application. Electrodes can be placed next to or directly on 
A

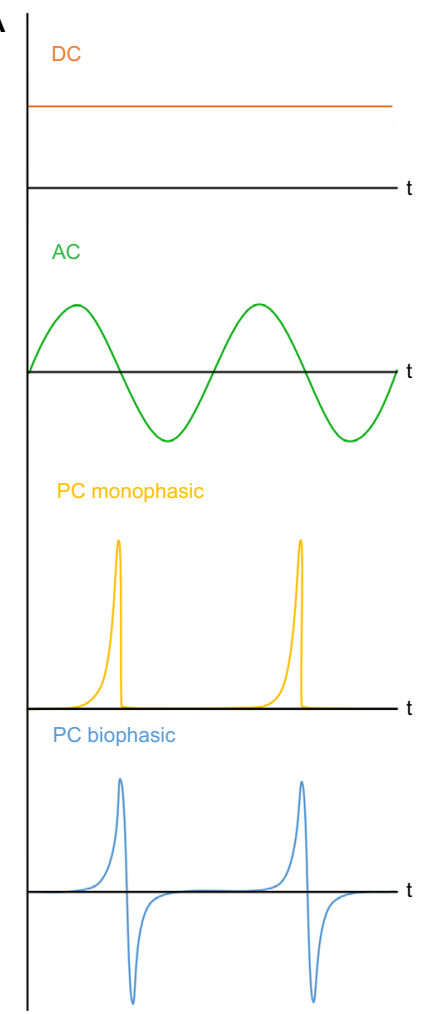

B

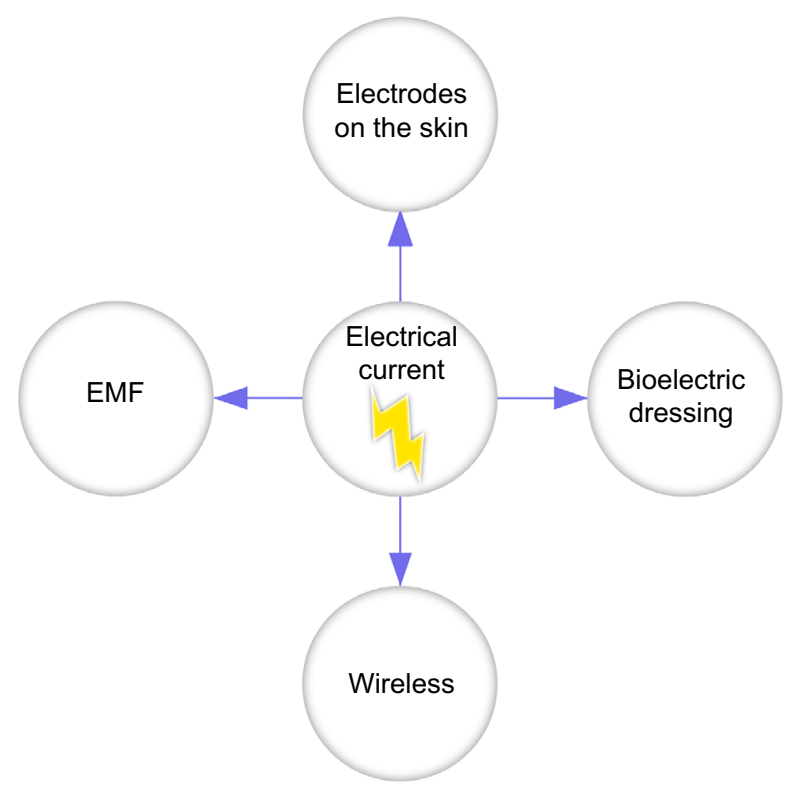

Figure 5 Types of electrical current and their different methods of application.

Notes: Four main types of current have been identified (A). Direct current (orange) is a continuous, unidirectional flow of charged particles that has no pulses and no waveform. DC is characterized by an amplitude and a duration. Its polarity remains constant during the stimulation. Alternative current (green) is a continuous bidirectional flow of charged particles in which a change in direction of flow occurs. AC stimulation is characterized by an amplitude, duration, and frequency. Pulsed current is a brief unidirectional or bidirectional flow of charged particles composed of short pulses separated by a longer off period of no current flow. PC stimulation is characterized by a frequency, duration, and pulse. The pulse is defined by a waveform, amplitude, and duration. The waveform can be monophasic (yellow), with constant polarity, or biphasic (blue), with alternating polarity. Electrical current can stimulate wound healing through different type of applications (B): electrodes on the skin, bioelectric dressing, wireless current stimulation, and EMF.

Abbreviations: EMF, electromagnetic field; DC, direct current; AC, alternative current; PC, pulsed current.

the cutaneous wound. A portable and independent dressing can also recover the wound and deliver a small current. ${ }^{71}$ Electromagnetic field and wireless microcurrent stimulation can allow the user to deliver a broad stimulation under the skin without touching it directly, and both have shown promising results on chronic wounds. ${ }^{60,71,72}$ The optimal approach and relevant parameters for a given condition is yet to be determined. However, studies at the cellular and systemic level have already shown that EST affects several cells and events involved in wound healing (Figure 6). During inflammation, ES induces a faster inflammatory response ${ }^{39}$ and an increased vascular vasodilatation ${ }^{73}$ that increases tissue oxygenation, ${ }^{37}$ blood flow, ${ }^{37,58,59,69}$ and skin temperature. ${ }^{59}$ During the proliferation phase, ES generates increased angiogenesis, ${ }^{30,36,57,59}$ collagen matrix formation, ${ }^{36-38}$ wound contraction, ${ }^{29,57}$ and reepithelialization. ${ }^{57,60}$ Finally, during the remodeling phase, increased cellular activity produces an advanced remodeling ${ }^{57}$ at a systemic level. RCT and in vivo trials have demonstrated the positive effects of EST on wounds (Tables 1 and 2).

\section{ES cellular and molecular mechanisms}

The mechanisms by which cells sense and respond to ES remain relatively unclear, it is believed that the extracellular electrical potential gradient generates an asymmetric signal between the two poles of the cells parallel to the electrical field lines. The cell membrane possesses an electrical potential that averages $70 \mathrm{mV}$ and variation of this potential influences the cell's general activity. If the membrane is electrically quiescent, the cell downregulates and its functional capacity diminishes. Conversely, with increased levels of electrical activity, upregulation occurs and the general cell activity level increases. ${ }^{26}$ It is believed that by using ES, we can influence the electrical activity of the cell membrane and induce specific cellular responses. To evaluate how cells 


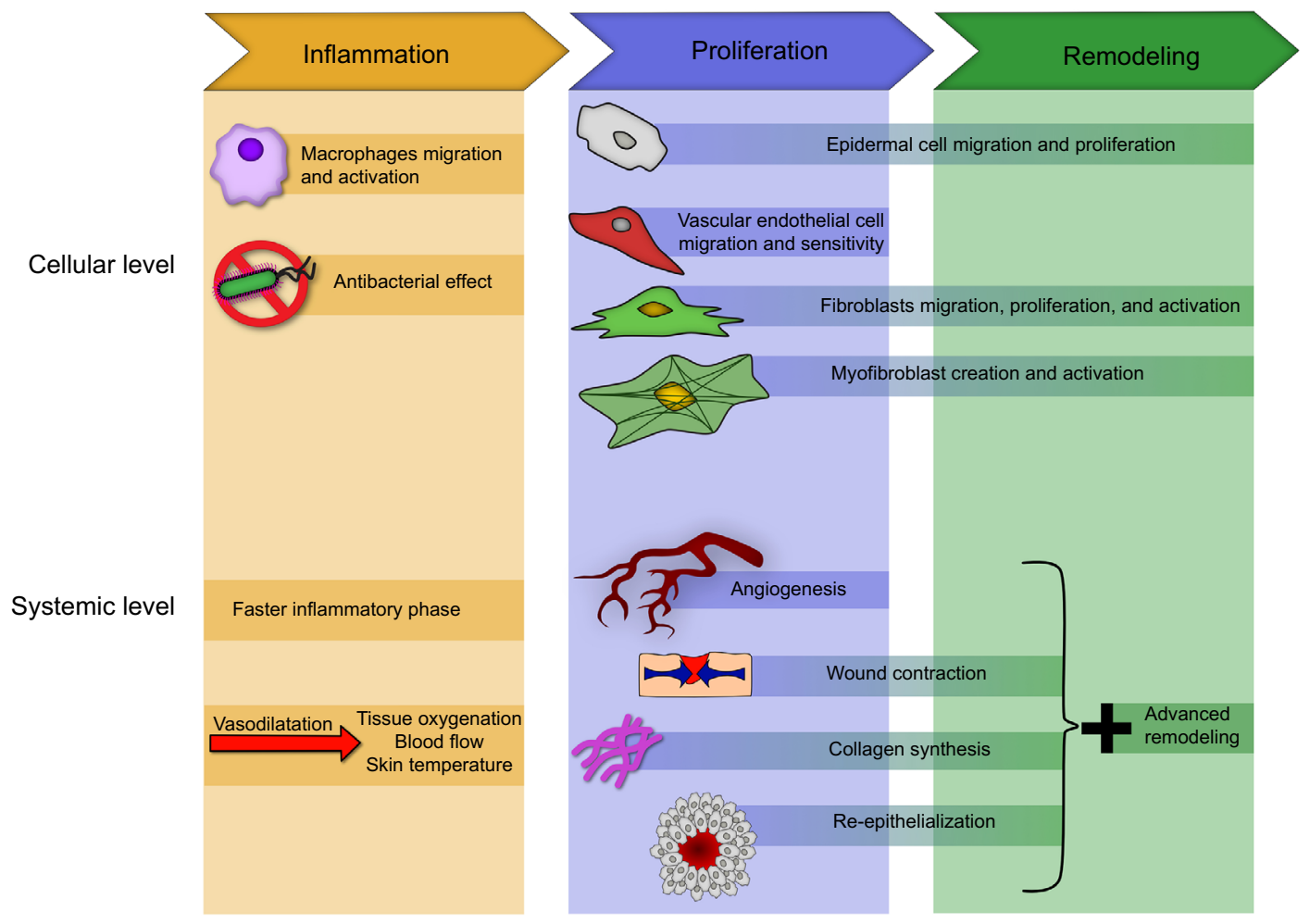

Figure 6 Reported effects of ES on wound healing at the cellular and systemic level during inflammation (yellow), proliferation (blue), and remodeling (green).

Notes: During inflammation, ES increases macrophages migration and activity and decreases bacterial proliferation at the cellular level. At a systemic level, it induces a faster inflammatory response and an increased vascular vasodilatation that increases tissue oxygenation, blood flow, and skin temperature. During the proliferation phase, ES increase the migratory response and activity level of epidermal cells, endothelial cells, fibroblasts, and myofibroblasts. At the systemic level, it generates increased angiogenesis, collagen matrix formation, wound contraction, and reepithelialization. Finally, during the remodeling phase, the activity of fibroblasts and myofibroblasts is enhanced at a cellular level and produces an advanced remodeling at a systemic level.

Abbreviation: ES, electrical stimulation.

Table I Animal in vivo studies testing the effects of electrical stimulation on wound healing

\begin{tabular}{|c|c|c|c|}
\hline Type of ES & Type of wound & Animal & Results \\
\hline $\mathrm{DC}^{35}$ & Incision wound & Pig & $\begin{array}{l}\text { Increased wound closure, increase of fibroblasts collagen, no difference in } \\
\text { microvessel number }\end{array}$ \\
\hline $\mathrm{DC}^{39}$ & Incision wound & Rat & Decrease of PMN and macrophages, increase of fibroblasts \\
\hline $\mathrm{DC}$ or $\mathrm{AC}^{37}$ & Incision wound & Pig & $\begin{array}{l}\text { Reduced healing time and increased perfusion, } D C \text { reduced wound area more } \\
\text { rapidly, } A C \text { reduced the wound volume more rapidly }\end{array}$ \\
\hline $\mathrm{DC}$ or $\mathrm{PC}^{28}$ & Incision wound & Rat & Increased biomechanical properties, collagen density, and wound closure \\
\hline $\mathrm{PC}^{31}$ & Incision wound & Mice & Acceleration of healing in $0.9-1.9 \mathrm{kV} / \mathrm{m}$ and suppression in $10 \mathrm{kV} / \mathrm{m}$ \\
\hline $\mathrm{PC}^{40}$ & Diabetic excision wound & Mice & Altered collagen deposition and cell number \\
\hline $\mathrm{PC}^{35}$ & Incision wound & Pig & Greater and faster wound surface area \\
\hline $\mathrm{PC}^{29}$ & Incision wound & Rabbit & Increased number of fibroblasts and higher tensile strength \\
\hline $\mathrm{PC}^{30}$ & Incision wound & Rat & Increase of blood vessels and fibroblasts \\
\hline $\mathrm{PC}^{33}$ & Diabetic incision wound & Rat & Increase wound healing, upregulation of collagen I and TGF \\
\hline $\mathrm{PC}^{36}$ & Ischemic model & Rabbit & Increase of VEGF and collagen IV and activity of collagen I and V \\
\hline TENS $^{34}$ & Skin flap & Rat & Increased wound closure \\
\hline TENS $^{32}$ & Incision wounds & Rats & $\begin{array}{l}\text { Proinflammatory cytokines reduction, and increased wound closure, } \\
\text { reepithelialization, and granulation tissue formation }\end{array}$ \\
\hline
\end{tabular}

Abbreviations: AC, alternative current; DC, direct current; ES, electrical stimulation; PC, pulsed current; PMN, polymorphonuclear leukocytes; TENS, transcutaneous electrical nerve stimulation; TGF, transforming growth factor; VEGF, vascular endothelial growth factor.

respond when exposed to an electrical current, experiments have been performed in electrotaxis chambers ${ }^{74}$ (Figure 7) and specifically designed culture plates. ${ }^{75,76}$ At the cellular level, EC may affect the ion channels and/or the membrane receptors, which constantly monitors the cell response to the microenvironment. Under an EC, both ion channels and transport proteins are activated and reorganized across the cell, independently of the external chemical gradient 


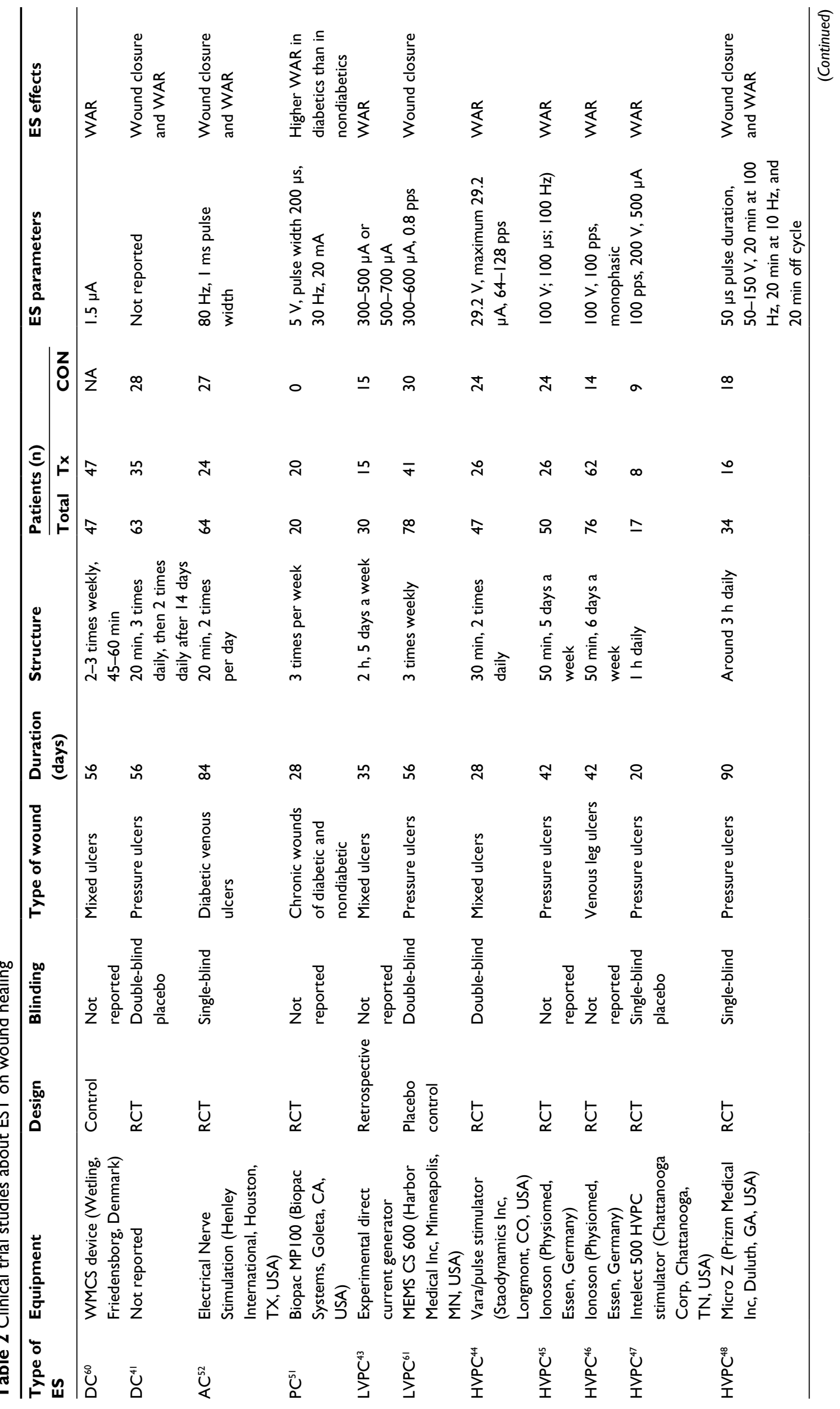







and ionic flow, to contribute toward intracellular polarization and cellular response. ${ }^{77}$ Intracellular pathways, such as phosphatidylinositol-3-OH kinase, ${ }^{20,78,79}$ and elements, such as golgi apparatus, ${ }^{10,19}$ seem to play a role in the galvanotaxis response.

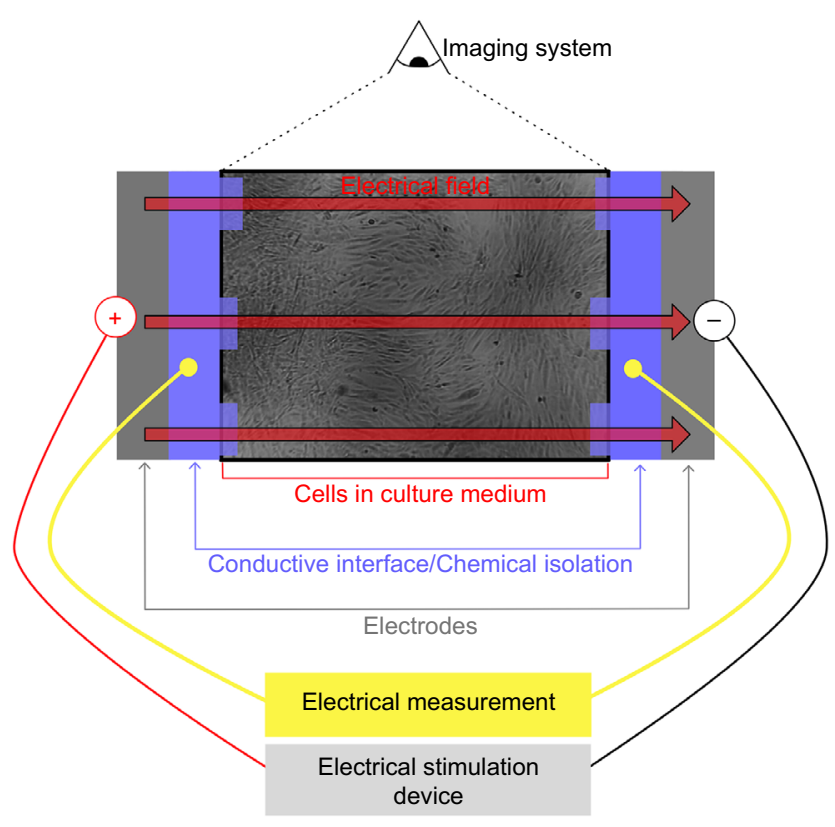

Figure 7 This experimental setup has been reported by Farina et $\mathrm{al}^{70}$ and has been used in several other articles.

Notes: The cell culture (blue) is done within an electrotactic chamber that isolates it from the outside (usually a modified well plate). The electrodes from the ES device are stimulating the cells through a conductive interface (blue) to the cell culture to avoid any electrochemical products in the cell culture. The electricity delivered is followed with an electrical measurement system (yellow), such as an oscilloscope. Finally, the evolution of the cells is tracked with a microscope (green) and the images are stored in a computer. Data from Song et al. ${ }^{74}$

Abbreviation: ES, electrical stimulation.
Individually, each cell type exhibits specific behaviors under ES and no ES displays a significant reduction of cell viability or cytotoxic effect. First, the polarity of the EC directs the cell migration and splits them in two groups, the one migrating toward the anode and the one migrating toward the cathode (Figure 8A). In a monolayer organization, cells also exhibit polarity-dependent behaviors ${ }^{19,20}$ (Figure 8B). In a scratch assay, a monolayer of corneal epithelium cells moved into the wounds in a coordinated manner without EC and faster with one that possessed the same polarity as the natural endogenous EC. Reversely, when applied opposite to the normal healing direction, the EC directed the cells at the wound edge, away from the wound, opening the wound. The same effect has been reported with a monolayer of fibroblasts ${ }^{19}$ (Figure 8C).

Furthermore, other outcomes have been used in vitro to measure the cell activity under EC. Under EC, fibroblasts proliferate, elongate, and reorient in vitro. ${ }^{10-12,14}$ Electrically stimulated fibroblasts seem to have a higher contractile behavior and higher fibroblast to myofibroblast transdifferentiation. ${ }^{11} \mathrm{DC}, \mathrm{AC}$, and $\mathrm{PC}$ have exhibited highly differential effects on fibroblasts in an in vitro study, where at high intensity and frequencies, the PC maximally downregulates collagen I and have a lower cytotoxic effect than $\mathrm{AC}$ and DC. ${ }^{13}$ At the wound site, enhanced fibroblast activities with DC, PC, and HVPC have also been reported in vivo, resulting in an increased fibroblast number, ${ }^{29,39}$ collagen synthesis, ${ }^{13,29,33,36,38}$ myofibroblast creation, and tensile strength. ${ }^{29}$ HVPC on diabetic rats has shown accelerated wound healing and restoration of the expression levels
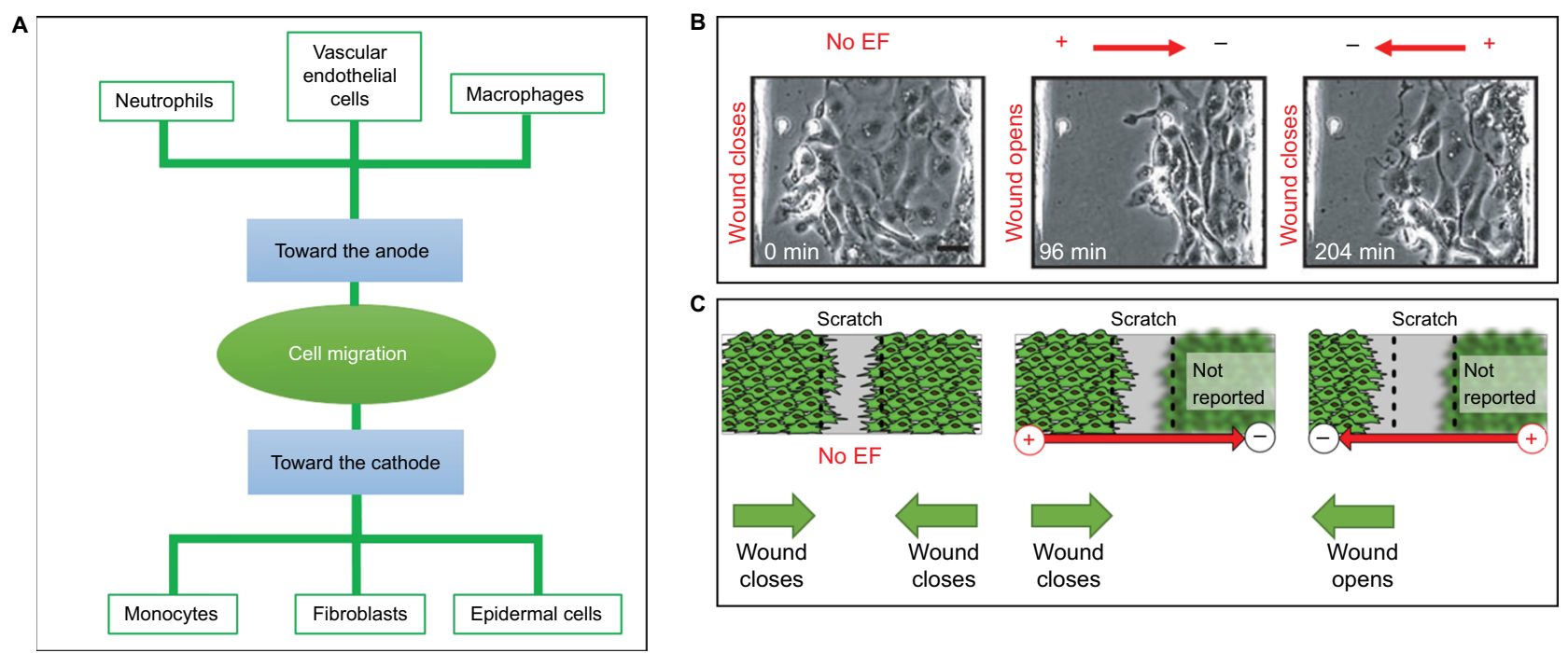

Figure $\mathbf{8}$ The polarity of the electrical current is a key feature in wound healing.

Notes: In isolated cell culture, neutrophils, vascular endothelial cells, and macrophages migrate toward the anode, and monocytes, fibroblasts, and epidermal cells toward the cathode (A). The polarity of the applied electrical current directly affects the direction of the cell migration on a scratch assay with a monolayer of corneal epithelial cells (B) and fibroblasts (C). Figure B adapted by permission from Macmillan Publishers Ltd: Nature. Zhao M, Song B, Pu J, et al. Electrical signals control wound healing through phosphatidylinositol-3-OH kinase-gamma and PTEN. 2006;442(7I0I):457-460. Copyright 2006. Available from http://www.nature.com/.20 Figure C data from Pu and Zhao. ${ }^{19}$ 
of collagen I and transforming growth factor, suggesting reactivation of the fibroblast activities. ${ }^{33}$ Under ES, vascular endothelial cells have also reported changes in cell elongation and orientation ${ }^{24-26}$ and upregulation of the levels of VEGF and IL-8 receptors. ${ }^{24}$ Recent studies have also tested the effects of ES on macrophages that exhibit enhanced phagocytic activity ${ }^{9}$ and platelets that display growth factors releases. ${ }^{80}$

Severe bacterial invasion can arrest the healing process and lead to chronic wound. Traditionally, systemic antibiotic treatments are used to treat severe infection. However, overuse of antibiotics can increase the bacterial resistance and lead to inefficient antibiotics. It is believed that ES may impose a bacteriostatic effect on microbes and bacteria that commonly colonize or infect wounds. ${ }^{21}$ Studies have shown that HVPC and DC kill or inhibit the proliferation of common wound pathogens, ${ }^{22,23}$ such as Staphylococcus aureus, Escherichia coli, and Pseudomonas aeruginosa. DC, HVPC, and LVPC have been tested in vitro on $S$. aureus. ${ }^{23}$ Apparently, HVPC and DC treatments have a significant inhibitory effect compared to LVPC. Moreover, no difference in bacterial growth inhibition was found when varying polarity and time of ES. At present, we are unclear as to why the ES seems to induce an antibacterial effect by direct or indirect mechanisms. The electrical current may directly disrupt the bacterial membrane or block its proliferation. Indirectly, the electrical current may induce a change of $\mathrm{pH}$ or temperature within the wound, a production of electrolysis products, or an increased migration of macrophages and leukocytes, resulting in an antibacterial effect.

\section{Angiogenesis: friend or foe?}

Angiogenesis is a key event in wound healing. While insufficient angiogenesis can lead to chronic wound formation, aggressive angiogenesis can lead to abnormal scarring. Thus, spatiotemporal control of EST to enhance angiogenesis is crucial. Several studies on animal models and clinical trials have shown that ES increases the level of VEGF and the number of blood vessels in the wound. ${ }^{30,58,59,66,73}$ Higher levels of VEGF linked to enhancing angiogenesis and advanced healing have been reported in the stimulated arm of each patient. VEGF is the most used angiogenic marker as it presents all the characteristics of a specific angiogenic factor ${ }^{81}$ and is predominantly produced by macrophages, platelets, endothelial cells, epidermal cells, fibroblasts, myofibroblasts, and mast cells. ${ }^{82}$ Indirectly, increased angiogenesis can facilitate local tissue oxygenation.

\section{Electrotherapy: the path to regeneration beyond repair?}

Salamanders and newts exhibit impressive regenerative ability that is divided into three phases: wound healing, dedifferentiation, and redevelopment, where they can regrow a whole limb. Humans are limited in repairing the localized damaged area. Both human repair and regenerative processes are regulated by ionic flows and endogenous electrical current. However, the evolution of the endogenous electrical current is distinctly different in regenerating and nonregenerating species (Figure 9). In nonregenerative species, the positive current decreases simultaneously as the wound heals. However, in regenerative species, the initial positive polarity of the injured tissue sharply reverses to a high negative polarity that gradually reduces as the damaged area regenerates. ${ }^{83}$ Particularly, the regeneration of the limb seems to be stopped if the polarity of the electrical current does not reverse. Recently, an in vivo experimentation on 90 tendons of rabbits has linked variation in the healing response with the polarity of the exogenous ES. ${ }^{27}$ Even if both cathodal and anodal stimulation exhibited accelerated healing rate, cathodal (negative) ES showed more significant improvements than anodal (positive) ES in the first 3 weeks, while anodal ES showed more significant improvement after 3 weeks. Cathodal stimulation may promote and attract macrophages in the early stage of wound healing, resulting in a faster inflammatory phase, and anodal stimulation may promote and attract fibroblasts in the late stage of wound healing, resulting in advanced remodeling phase. Recognition of the ES polarity dependence on the stage of the wound could lead to better healing response and less scar formation.

\section{Smart materials, technology, and ES}

Electrotherapy could be combined with the state-of-the-art technologies for potentially superior therapeutic effects in wound healing and skin regeneration (Figure 10). For instance, researchers have set up human skin-based triboelectric nanogenerators ${ }^{84}$ and smart skins ${ }^{85}$ that can harvest the biomechanical energy to produce renewable electricity. Such technologies could power a bioelectric dressing that would stimulate the wound. New dressings made of conductive and inherently antibacterial materials, such as electroactive doped polyurethane/siloxane membrane ${ }^{86}$ can work simultaneously with electrotherapy by restoring the physiological homeostasis at the wound site and biomimicking the current of injury. Moreover, electrically controlled drug delivery could be achieved within a dressing or scaffold by using electrically responsive hydrogels ${ }^{87,88}$ or graphene oxide nanocomposite 
A

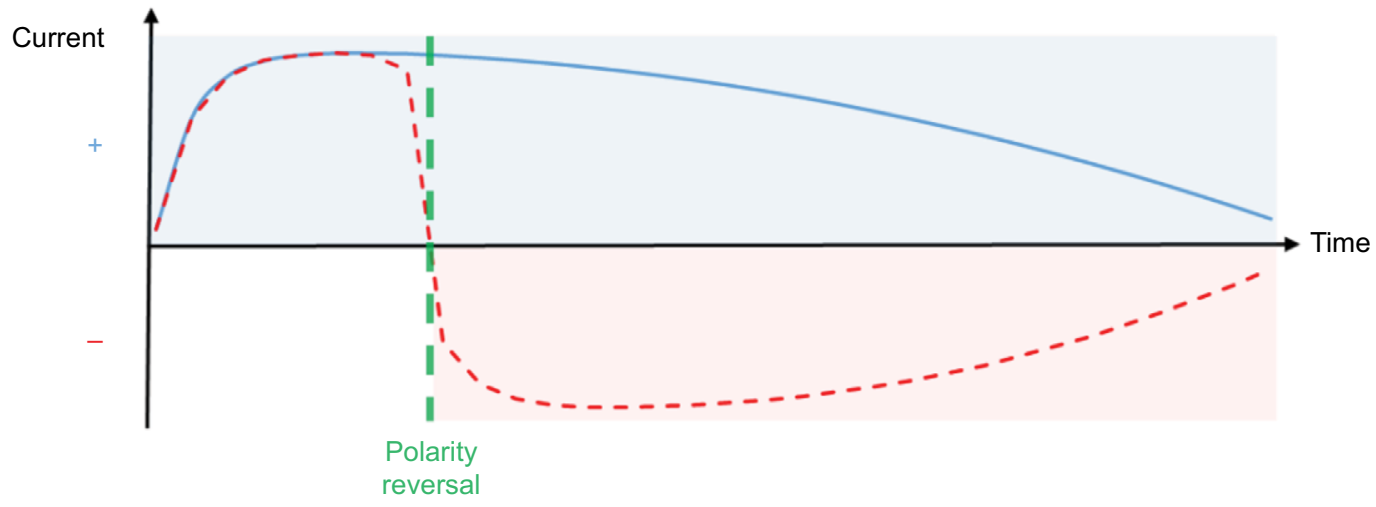

B

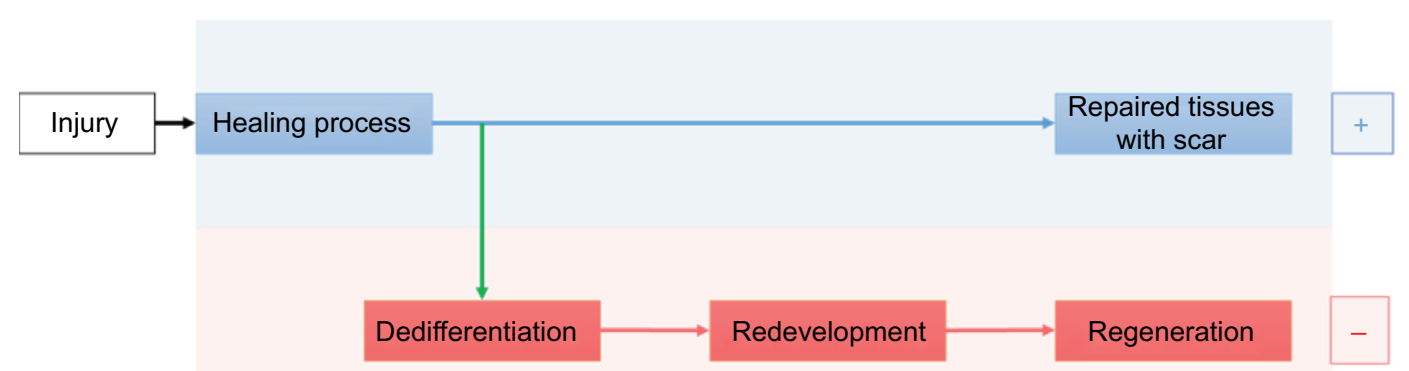

Figure 9 Evolution of the current of injury in regenerative and nonregenerative species after injury (A). In nonregenerative species (blue), the current stays positive and gradually reduces as the wound heals. In regenerative species (red), a polarity reversal (green) occurs while healing. The negative current gradually reduces as the damaged area regenerates. After an injury (B), both regenerative and nonregenerative species exhibit a healing process. After the polarity reversal of the regenerative species, a dedifferentiation, where cells lose their specialized characteristics and migrate, occurs. Then the limb regrows during the redevelopment and leads to a complete regeneration, where nonregenerative species have maintained their positive current and repaired tissues with a scar.

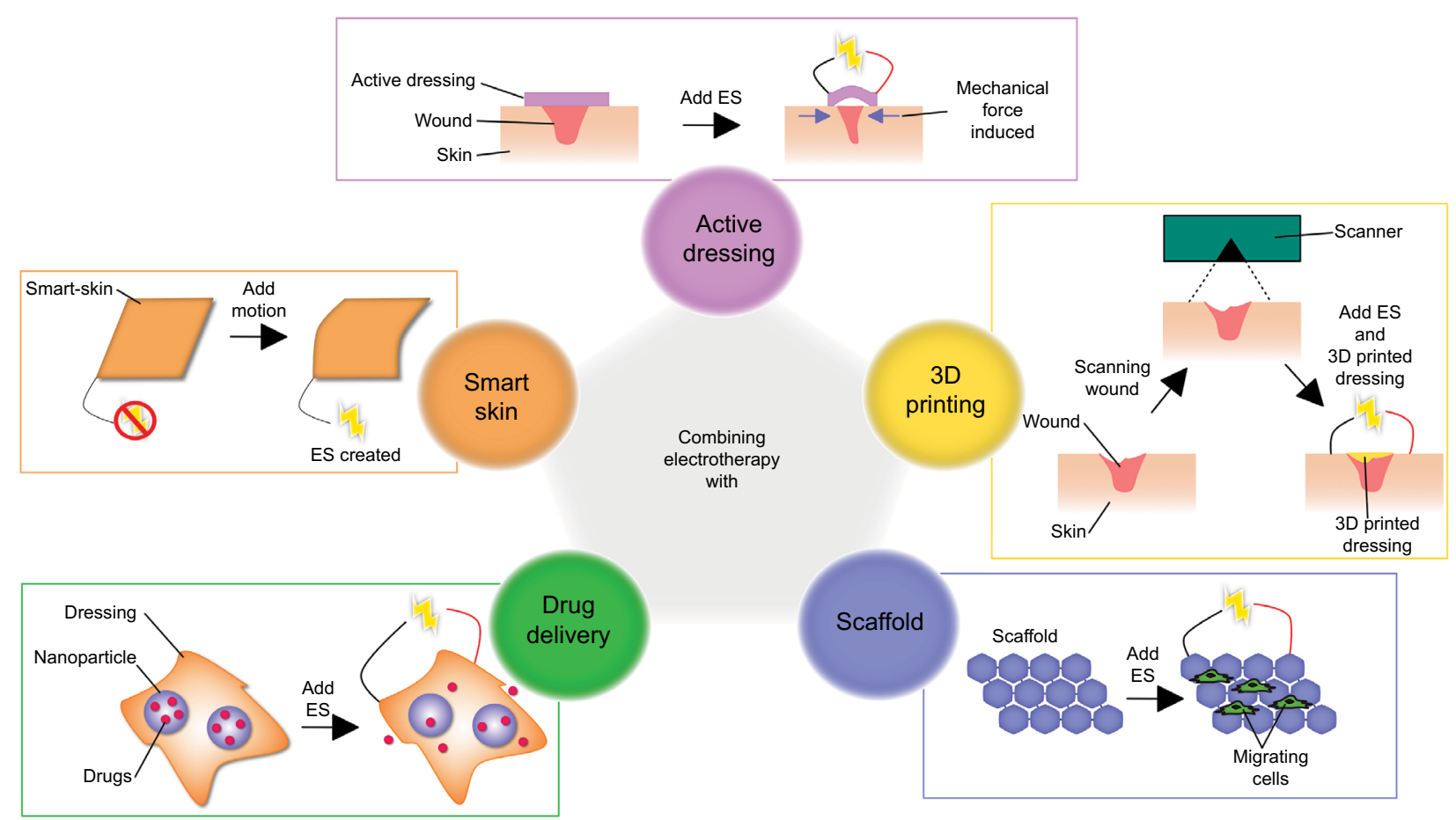

Figure 10 Electrotherapy can be combined with state of the art technology, such as active dressings, 3D printing, scaffold, drug delivery, or smart skin. Abbreviation: ES, electrical stimulation. 
films ${ }^{89}$ filled with nanoparticle system containing the drug. With this approach, drug release could be modulated by the endogenous or exogenous electrical current. Using a scaffold, such as collagen/gold nanoparticle scaffolds ${ }^{90}$ or injectable microporous gel scaffolds, ${ }^{91}$ could provide a biodegradable structure and accelerate cell migration to the wound site, following which an ES can enhance the cellular activity within the scaffold. Specific materials properties can be combined with EST for better aesthetics of the wound during the treatment, by creating a layer on the skin to disguise or "hide" the wound. ${ }^{92} 3 \mathrm{D}$ printing is a relatively novel method that enables bespoke therapy and offers an opportunity to 3D print skin scaffolds using the patient's own cells ${ }^{93}$ as well as the ability to make bespoke patches. ${ }^{94}$ Shape memory polymer composites, ${ }^{95}$ which have properties similar to uninjured skin, are of great interest to generate electricity-dependent mechanical and thermal stresses on the wound. These stresses would depend on the intensity of the current of injury, and thus, would evolve during each phase of the healing process.

\section{Role of magnetic field}

Furthermore, significant beneficial effects have been reported with the use of magnetic field in pain management, bone fracture, and wound healing. ${ }^{96}$ It is particularly intriguing when we know that magnetic and electric forces are linked by the Maxwell's equations. Every electric field generates a magnetic field in the surrounding environment and vice versa. Scientists refer to the use of electric and magnetic fields in medicine as the electromagnetic field therapy. ${ }^{96}$ In vitro, magnetic field seems to elicit changes in cells of the immune systems through $\mathrm{Ca}^{2+}$ signaling, including upregulated cytokine synthesis and increased cell proliferation. The electromagnetic field generates an ionic flow under the skin that is similar to the one seen in electrotherapy. However, more studies are needed to understand the mechanisms underlying the response of biological tissue to both electric and magnetic fields.

\section{Conclusion and the future}

Electrotherapy and associated smart materials and technologies promise to improve chronic wound healing strategies and can be potentially established as a clinically robust and commercially viable system for wound healing that will make a great impact in global health care and economy. However, there are considerable variations in parameters, modes, dosing, and duration of treatment that lead to complications in comparison of the data with a need for more well-designed clinical trials.
The healing process undergoes different stages and each stage involves a different and interlinked set of cellular events. More studies are warranted to delineate their mechanism and the influence of ES on them. Recognizing the type of current and the corresponding cellular activity, which it most influences may help to present personalized treatment to specific types of wounds. Electrotherapy devices at the current age of digital health care, together with developments in responsive smart materials and technologies, could enable continuous monitoring of the status of patient's wound, allowing instant feedback responses, thus allowing the health care provider to choose with ease, preselected parameters that would optimally accelerate wound healing. These possible innovations could have an impact on other related diseases, such as Raynaud's disease, necrotizing fasciitis, or cosmetic concerns, such as chickenpox scars, acne, keloid scar, or rosacea. Better understanding and optimization of EST will interest multidisciplinary research groups including surgical, biochemical and translational sciences to apply the great potential of EST in regenerative medicine.

\section{Acknowledgments}

The authors gratefully acknowledge Globe Microsystems Ltd for their sponsorship to support JH and studies on wound healing. AdM is a coinvestigator of Engineering and Physical Sciences Research Council (EPSRC) project EP/L020904/1. The authors gratefully acknowledge Dr Vittorio Malaguti for his most helpful and insightful comments on the early drafts of this article.

\section{Disclosure}

The authors report no conflicts of interest in this work.

\section{References}

1. Kerr M. Foot care for people with diabetes: the economic case for change. NHS Diabetes; 2012. Available from: https://www.diabetes. org.uk/Documents/nhs-diabetes/footcare/footcare-for-people-withdiabetes.pdf. Accessed June 1, 2016.

2. Armstrong DG, Kanda VA, Lavery LA, Marston W, Mills JL Sr, BoultonAJ. Mind the gap: disparity between research funding and costs of care for diabetic foot ulcers. Diabetes Care. 2013;36(7):1815-1817.

3. Gottrup F, Apelqvist J, Price P; European Wound Management Association Patient Outcome Group. Outcomes in controlled and comparative studies on non-healing wounds: recommendations to improve the quality of evidence in wound management. JWound Care, 2010;19(6):237-268.

4. Diabetes-UK. State of the Nation: England; 2013: 1-32.

5. Christian LM, Graham JE, Padgett DA, Glaser R, Kiecolt-Glaser JK. Stress and wound healing. Neuroimmunomodulation. 2006;13(5-6): 337-346.

6. Guo S, Dipietro L. Factors affecting wound healing. $J$ Dent Res. 2010;89(3):219-229.

7. Eltinge EM, Cragoe EJ Jr, Vanable JW Jr. (1986). Effects of amiloride analogues on adult Notophthalmus viridescens limb stump currents. Comp Biochem Physiol A Comp Physiol. 1986;84(1):39-44. 
8. Foulds IS, Barker AT. Human skin battery potentials and their possible role in wound healing. Br J Dermatol. 1983;109(5):515-522.

9. Hoare JI, Rajnicek AM, McCaig CD, Barker RN, Wilson HM. Electric fields are novel determinants of human macrophage functions. J Leukoc Biol. 2016;99(6):1141-1151.

10. Kim MS, Lee MH, Kwon BJ, Koo MA, Seon GM, Park JC. Golgi polarization plays a role in the directional migration of neonatal dermal fibroblasts induced by the direct current electric fields. Biochem Biophys Res Commun. 2015;460(2):255-260.

11. Rouabhia M, Park H, Meng S, Derbali H, Zhang Z. Electrical stimulation promotes wound healing by enhancing dermal fibroblast activity and promoting myofibroblast transdifferentiation. PLoS One. 2013; 8(8): 71660

12. Rouabhia M, Park HJ, Zhang Z. Electrically activated primary human fibroblasts improve in vitro and in vivo skin regeneration. J Cell Physiol. 2016;231(8):1814-1821.

13. Sebastian A, Syed F, McGrouther DA, Colthurst J, Paus R, Bayat A. A novel in vitro assay for electrophysiological research on human skin fibroblasts: degenerate electrical waves downregulate collagen I expression in keloid fibroblasts. Exp Dermatol. 2011;20(1):64-68.

14. Wang Y, Rouabhia M, Zhang Z. Pulsed electrical stimulation benefits wound healing by activating skin fibroblasts through the TGF $\beta 1 /$ ERK/ NF-KB axis. Biochim Biophys Acta. 2016;1860(7):1551-1559.

15. Cohen DJ, James Nelson W, Maharbiz MM. Galvanotactic control of collective cell migration in epithelial monolayers. Nat Mater. 2014; 13(4):409-417.

16. Gao J, Raghunathan VK, Reid B, et al. Biomimetic stochastic topography and electric fields synergistically enhance directional migration of corneal epithelial cells in a MMP-3-dependent manner. Acta Biomater. 2015;12:102-112.

17. Li L, Gu W, Du J, et al. Electric fields guide migration of epidermal stem cells and promote skin wound healing. Wound Repair Regen. 2012;20(6):840-851.

18. Nishimura KY, Isseroff RR, Nuccitelli R. Human keratinocytes migrate to the negative pole in direct current electric fields comparable to those measured in mammalian wounds. J Cell Sci. 1996;109(Pt 1):199-207.

19. Pu J, Zhao M. Golgi polarization in a strong electric field. J Cell Sci. 2005;118(Pt 6):1117-1128.

20. Zhao M, Song B, Pu J, et al. Electrical signals control wound healing through phosphatidylinositol-3-OH kinase-gamma and PTEN. Nature. 2006;442(7101):457-460.

21. Asadi MR, Torkaman G. Bacterial inhibition by electrical stimulation. Adv Wound Care (New Rochelle). 2014;3(2):91-97.

22. Gomes RC, Brandino HE, de Sousa NT, Santos MF, Martinez R, Guirro RR. Polarized currents inhibit in vitro growth of bacteria colonizing cutaneous ulcers. Wound Repair Regen. 2015;23(3):403-411.

23. Merriman HL, Hegyi CA, Albright-Overton CR, Carlos J Jr, Putnam RW, Mulcare JA. A comparison of four electrical stimulation types on Staphylococcus aureus growth in vitro. J Rehabil Res Dev. 2004; 41(2):139-146.

24. Bai H, Forrester JV, Zhao M. DC electric stimulation upregulates angiogenic factors in endothelial cells through activation of VEGF receptors. Cytokine. 2011;55(1):110-115.

25. Bai H, McCaig CD, Forrester JV, Zhao M. DC electric fields induce distinct preangiogenic responses in microvascular and macrovascular cells. Arterioscler Thromb Vascu Biol. 2004;24(7):1234-1239.

26. Zhao M, Bai H, Wang E, Forrester JV, McCaig CD. Electrical stimulation directly induces pre-angiogenic responses in vascular endothelial cells by signaling through VEGF receptors. J Cell Sci. 2004;117(Pt 3): 397-405.

27. Ahmed AF, Elgayed SSA, Ibrahim IM. (2012). Polarity effect of microcurrent electrical stimulation on tendon healing: biomechanical and histopathological studies. $J A d v$ Res. 2012;3(2):109-117.

28. Asadi MR, Torkaman G, Hedayati M, Mofid M. Role of sensory and motor intensity of electrical stimulation on fibroblastic growth factor- 2 expression, inflammation, vascularization, and mechanical strength of full-thickness wounds. J Rehabil Res Dev. 2013;50(4): 489-498.
29. Bayat M, Asgari-Moghadam Z, Maroufi M, Rezaie FS, Bayat M, Rakhshan M. Experimental wound healing using microamperage electrical stimulation in rabbits. J Rehabil Res Dev. 2006;43(2):219-226.

30. Borba GC, Hochman B, Liebano RE, Enokihara MM, Ferreira LM. Does preoperative electrical stimulation of the skin alter the healing process? J Surg Res. 2011;166(2):324-329.

31. Cinar K, Comlekci S, Senol N. Effects of a specially pulsed electric field on an animal model of wound healing. Lasers Med Sci. 2009;24(5): 735-740.

32. Gurgen SG, Sayin O, Cetin F, Tuc Yucel A. Transcutaneous electrical nerve stimulation (TENS) accelerates cutaneous wound healing and inhibits pro-inflammatory cytokines. Inflammation. 2014;37(3):775-784.

33. Kim TH, Cho HY, Lee SM. High-voltage pulsed current stimulation enhances wound healing in diabetic rats by restoring the expression of collagen, $\alpha$-smooth muscle actin, and TGF- $\beta 1$. Tohoku J Exp Med. 2014;234(1):1-6.

34. Liebano RE, Abla LE, Ferreira LM. Effect of high frequency transcutaneous electrical nerve stimulation on viability of random skin flap in rats. Acta Cir Bras. 2006;21(3):133-138.

35. Mehmandoust FG, Torkaman G, Firoozabadi M, Talebi G. Anodal and cathodal pulsed electrical stimulation on skin wound healing in guinea pigs. J Rehabil Res Dev. 2007;44(4):611-618.

36. Morris KA, McGee MF, Jasper JJ, Bogie KM. Evaluation of electrical stimulation for ischemic wound therapy: a feasibility study using the lapine wound model. Arch Dermatol Res. 2009;301(4):323-327.

37. Reger SI, Hyodo A, Negami S, Kambic HE, Sahgal V. Experimental wound healing with electrical stimulation. Artif Organs. 1999;23(5): $460-462$.

38. Talebi G, Torkaman G, Firoozabadi M, Shariat S. Effect of anodal and cathodal microamperage direct current electrical stimulation on injury potential and wound size in guinea pigs. $J$ Rehabil Res Dev. 2008; 45(1):153-159.

39. Taskan I, Ozyazgan I, Tercan M, et al. A comparative study of the effect of ultrasound and electrostimulation on wound healing in rats. Plast Reconstr Surg. 1997;100(4):966-972.

40. Thawer HA, Houghton PE. Effects of electrical stimulation on the histological properties of wounds in diabetic mice. Wound Repair Regen. 2001;9(2):107-115.

41. Adunsky A, Ohry A; DDCT Group. Decubitus direct current treatment (DDCT) of pressure ulcers: results of a randomized double-blinded placebo controlled study. Arch Gerontol Geriatr. 2005;41(3):261-269.

42. Ahmad E. High-voltage pulsed galvanic stimulation: effect of treatment duration on healing of chronic pressure ulcers. Ann Burns Fire Disasters. 2008;21(3):124-128.

43. Carley PJ, Wainapel SF. Electrotherapy for acceleration of wound healing: low intensity direct current. Arch Phys Med Rehabil. 1985;66(7):443-446.

44. Feedar JA, Kloth LC, Gentzkow GD. Chronic dermal ulcer healing enhanced with monophasic pulsed electrical stimulation. Phys Ther. 1991;71(9):639-649.

45. Franek A, Kostur R, Polak A, et al. Using high-voltage electrical stimulation in the treatment of recalcitrant pressure ulcers: results of a randomized, controlled clinical study. Ostomy Wound Manage. 2012; 58(3):30-44.

46. Franek A, Polak A, Kucharzewski M. Modern application of high voltage stimulation for enhanced healing of venous crural ulceration. Med Eng Phys. 2000;22(9):647-655.

47. Griffin JW, Tooms RE, Mendius RA, Clifft JK, Vander Zwaag R, el-Zeky F. Efficacy of high voltage pulsed current for healing of pressure ulcers in patients with spinal cord injury. Phys Ther. 1991;71(6):433-442; discussion 442-434.

48. Houghton PE, Campbell KE, Fraser CH, et al. Electrical stimulation therapy increases rate of healing of pressure ulcers in community-dwelling people with spinal cord injury. Arch Phys Med Rehabil. 2010;91(5): 669-678.

49. Houghton PE, Kincaid CB, Lovell M, et al. Effect of electrical stimulation on chronic leg ulcer size and appearance. Phys Ther. 2003; 83(1):17-28. 
50. Janković A, Binić I. Frequency rhythmic electrical modulation system in the treatment of chronic painful leg ulcers. Arch Dermatol Res. 2008;300(7):377-383.

51. Lawson D, Petrofsky JS. A randomized control study on the effect of biphasic electrical stimulation in a warm room on skin blood flow and healing rates in chronic wounds of patients with and without diabetes. Med Sci Monit. 2007;13(6):CR258-CR263.

52. Lundeberg TC, Eriksson SV, Malm M. Electrical nerve stimulation improves healing of diabetic ulcers. Ann Plast Surg. 1992;29(4):328-331.

53. Magnoni C, Rossi E, Fiorentini C, Baggio A, Ferrari B, Alberto G. Electrical stimulation as adjuvant treatment for chronic leg ulcers of different aetiology: an RCT. J Wound Care. 2013;22(10):525-526, 528-533.

54. Margara A, Boriani F, Obbialero FD, Bocchiotti MA. Frequency rhythmic electrical modulation system in the treatment of diabetic ulcers. Chirurgia. 2008;21(6):311-314.

55. Peters EJ, Lavery LA, Armstrong DG, Fleischli JG. Electric stimulation as an adjunct to heal diabetic foot ulcers: a randomized clinical trial. Arch Phys Med Rehabil. 2001;82(6):721-725.

56. Santamato A, Panza F, Fortunato F, et al. Effectiveness of the frequency rhythmic electrical modulation system for the treatment of chronic and painful venous leg ulcers in older adults. Rejuvenation Res. 2012;15(3):281-287.

57. Sebastian A, Syed F, Perry D, et al. Acceleration of cutaneous healing by electrical stimulation: degenerate electrical waveform down-regulates inflammation, up-regulates angiogenesis and advances remodeling in temporal punch biopsies in a human volunteer study. Wound Repair Regen. 2011;19(6):693-708.

58. Ud-Din S, Perry D, Giddings P, et al. Electrical stimulation increases blood flow and haemoglobin levels in acute cutaneous wounds without affecting wound closure time: evidenced by non-invasive assessment of temporal biopsy wounds in human volunteers. Exp Dermatol. 2012;21(10):758-764.

59. Ud-Din S, Sebastian A, Giddings P, et al. Angiogenesis is induced and wound size is reduced by electrical stimulation in an acute wound healing model in human skin. PLoS One. 2015;10(4):e0124502.

60. Wirsing PG, Habrom AD, Zehnder TM, Friedli S, Blatti M. Wireless micro current stimulation-an innovative electrical stimulation method for the treatment of patients with leg and diabetic foot ulcers. Int Wound J. 2015;12(6):693-698.

61. Wood JM, Evans PE 3rd, Schallreuter KU, et al. A multicenter study on the use of pulsed low-intensity direct current for healing chronic stage II and stage III decubitus ulcers. Arch Dermatol. 1993;129(8):999-1009.

62. Vieira AC, Reid B, Cao L, Mannis MJ, Schwab IR, Zhao M. Ionic components of electric current at rat corneal wounds. PLoS One. 2011; 6(2):e17411.

63. Reid B, Song B, McCaig CD, Zhao M. Wound healing in rat cornea: the role of electric currents. FASEB J. 2005;19(3):379-386.

64. McCaig CD, Rajnicek AM, Song B, Zhao M. Controlling cell behavior electrically: current views and future potential. Physiol Rev. 2005; 85(3):943-978.

65. Kloth LC. Electrical stimulation for wound healing: a review of evidence from in vitro studies, animal experiments, and clinical trials. Int J Low Extrem Wounds. 2005;4(1):23-44.

66. Ferroni P, Roselli M, Guadagni F, et al. Biological effects of a software-controlled voltage pulse generator (PhyBack PBK-2C) on the release of vascular endothelial growth factor (VEGF). In Vivo. 2005; 19(6):949-958.

67. Bevilacqua M, Dominguez LJ, Barrella M, Barbagallo M. Induction of vascular endothelial growth factor release by transcutaneous frequency modulated neural stimulation in diabetic polyneuropathy. J Endocrinol Invest. 2007;30(11):944-947.

68. Bocchi L, Evangelisti A, Barrella M, Scatizzi L, Bevilacqua M. Recovery of $0.1 \mathrm{~Hz}$ microvascular skin blood flow in dysautonomic diabetic (type 2) neuropathy by using Frequency Rhythmic Electrical Modulation System (FREMS). Med Eng Phys. 2010;32(4):407-413.
69. Cramp AF, Gilsenan C, Lowe AS, Walsh DM. The effect of high- and low-frequency transcutaneous electrical nerve stimulation upon cutaneous blood flow and skin temperature in healthy subjects. Clin Physiol. 2000;20(2):150-157.

70. Farina S, Casarotto M, Benelle $\mathrm{M}$, et al. A randomized controlled study on the effect of two different treatments (FREMS AND TENS) in myofascial pain syndrome. Eura Medicophys. 2004;40(4):293-301.

71. Harding AC, Gil J, Valdes J, Solis M, Davis SC. Efficacy of a bio-electric dressing in healing deep, partial-thickness wounds using a porcine model. Ostomy Wound Manage. 2012;58(9):50-55.

72. Weintraub MI, Wolfe GI, Barohn RA, et al. Static magnetic field therapy for symptomatic diabetic neuropathy: a randomized, doubleblind, placebo-controlled trial. Arch Phys Med Rehabil. 2015;84(5): 736-746.

73. Goldman R, Rosen M, Brewley B, Golden M. Electrotherapy promotes healing and microcirculation of infrapopliteal ischemic wounds: a prospective pilot study. Adv Skin Wound Care. 2004;17(6): 284-294.

74. Song B, Gu Y, Pu J, Reid B, Zhao Z, Zhao M. Application of direct current electric fields to cells and tissues in vitro and modulation of wound electric field in vivo. Nat Protoc. 2007;2(6):1479-1489.

75. Wang ET, Zhao M. Regulation of tissue repair and regeneration by electric fields. Chin J Traumatol. 2010;13(1):55-61.

76. Xiong GM, Do AT, Wang JK, Yeoh CL, Yeo KS, Choong C. Development of a miniaturized stimulation device for electrical stimulation of cells. J Biol Eng. 2015;9(1):14.

77. Caddy J, Wilanowski T, Darido C, et al. Epidermal wound repair is regulated by the planar cell polarity signaling pathway. Dev Cell. 2010;19(1):138-147.

78. Allen GM, Mogilner A, Theriot JA. Electrophoresis of cellular membrane components creates the directional cue guiding keratocyte galvanotaxis. Curr Biol. 2013;23(7):560-568.

79. Sun Y, Do H, Gao J, Zhao R, Zhao M, Mogilner A. Keratocyte fragments and cells utilize competing pathways to move in opposite directions in an electric field. Curr Biol. 2013;23(7):569-574.

80. Torres AS, Caiafa A, Garner AL, et al. Platelet activation using electric pulse stimulation: growth factor profile and clinical implications. J Trauma Acute Care Surg. 2014;77(3 Suppl 2):S94-S100.

81. Hoeben A, Landuyt B, Highley MS, Wildiers H, Van Oosterom AT, De Bruijn EA. (2004). Vascular endothelial growth factor and angiogenesis. Pharmacol Rev. 2004;56(4):549-580.

82. Barrientos S, Stojadinovic O, Golinko MS, Brem H, Tomic-Canic M. Growth factors and cytokines in wound healing. Wound Repair Regen, 2008;16(5):585-601.

83. Reid B, Song B, Zhao M. Electric currents in Xenopus tadpole tail regeneration. Dev Biol. 2009;335(1):198-207.

84. Yang Y, Zhang H, Lin ZH, et al. Human skin based triboelectric nanogenerators for harvesting biomechanical energy and as self-powered active tactile sensor system. ACS Nano. 2013;7(10):9213-9222.

85. Shi M, Zhang J, Chen H, et al. Self-powered analogue smart skin. ACS Nano. 2016;10(4):4083-4091.

86. Gharibi R, Yeganeh H, Rezapour-Lactoee A, Hassan ZM. (2015). Stimulation of wound healing by electroactive, antibacterial, and antioxidant polyurethane/siloxane dressing membranes: in vitro and in vivo evaluations. ACS Appl Mater Interfaces. 2015;7(43):24296-24311.

87. Ge J, Neofytou E, Cahill TJ 3rd, Beygui RE, Zare RN. Drug release from electric-field-responsive nanoparticles. ACS Nano. 2012;6(1): 227-233.

88. Murdan S. Electro-responsive drug delivery from hydrogels. J Control Release. 2003;92(1-2):1-17.

89. Weaver CL, LaRosa JM, Luo X, Cui XT. Electrically controlled drug delivery from graphene oxide nanocomposite films. ACS Nano. 2014;8(2):1834-1843.

90. Akturk O, Kismet K, Yasti AC, et al. Collagen/gold nanoparticle nanocomposites: a potential skin wound healing biomaterial. J Biomater Appl. 2016;31(2):283-301. 
91. Griffin DR, Weaver WM, Scumpia PO, Di Carlo D, Segura T. Accelerated wound healing by injectable microporous gel scaffolds assembled from annealed building blocks. Nat Mater. 2015;14(7):737-744.

92. Yu B, Kang SY, Akthakul A, et al. An elastic second skin. Nat Mater. 2016;15(8):911-918.

93. Chung E. PrintAlive 3D skin tissue printer wins Canadian Dyson Award. Available from: http://www.cbc.ca/news/technology/printalive-3d-skintissue-printer-wins-canadian-dyson-award-1.2770667
94. de Mel A. Three-dimensional printing and the surgeon. Br J Surg. 2016;103(7):786-788.

95. Shen Q, Trabia S, Stalbaum T, Palmre V, Kim K, Oh IK. A multiple-shape memory polymer-metal composite actuator capable of programmable control, creating complex 3D motion of bending, twisting, and oscillation. Sci Rep. 2016;6:24462.

96. Markov MS. Electromagnetic Fields in Biology and Medicine: CRC Press; 2015 


\section{Supplementary material}

Video SI The skin battery and the current of injury.

The Journal of Multidisciplinary Healthcare is an international, peerreviewed open-access journal that aims to represent and publish research in healthcare areas delivered by practitioners of different disciplines. This includes studies and reviews conducted by multidisciplinary teams as well as research which evaluates the results or conduct of such teams or health care processes in general. The journal covers a very wide range of areas and welcomes submissions from practitioners at all levels, from all over the world. The manuscript management system is completely online and includes a very quick and fair peer-review system. Visit http://www.dovepress.com/ testimonials.php to read real quotes from published authors. 